\title{
Clinical Characteristics of Pediatric with Germ Cell Tumor: Experience in a Developing Country
}

\author{
Lelani Reniarti, ${ }^{1}$ Anisah Febri, ${ }^{2}$ Nur Melani Sari ${ }^{1}$ \\ ${ }^{1}$ Department of Child Health Faculty of Medicine Universitas Padjadjaran/Dr. Hasan Sadikin \\ General Hospital, Bandung, Indonesia, ${ }^{2}$ Faculty of Medicine, Universitas Padjadjaran, Indonesia
}

\section{Abstract}

Background: Germ cell tumor (GCT) occurs in 3\% of pregnancy malignancies and increases by 15\% during adolescence. In developing countries, the five-year survival rate is $98 \%$ and $80 \%$ for GCT earlier stage and malignant tumor, respectively. This study aimed to gather information about clinical manifestations of GCT and to evaluate the treatment outcome in pediatric GCT patients at Dr. Hasan Sadikin General Hospital, Bandung, Indonesia.

Methods: A descriptive cross-sectional study design with a total sampling method was conducted using secondary data from the medical record of pediatric patients diagnosed with GCT from 2015 to 2018. Data on nutritional status, clinical characteristics, histopathology stage, hematological profiles, chemical markers, treatment methods, completeness of treatment, and outcome at the end of treatment were collected and presented using tables and charts.

Results: Of the 44 subjects, girls (77.3\%) were predominant, with a mean age of 2 years old and normal nutritional status (59.1\%). Patients generally had abdominal mass $(97.7 \%)$ and most had intragonadal GCT (95.5\%), with ovarium (76.2\%) as the most common location. The most frequent GCT histopathology was yolk sac tumor (34.1\%), with an Alpha-fetoprotein (AFP) level of $>100.000$ $(6.8 \%)$. Almost all patients $(97.7 \%)$ had undergone surgery; however, $47 \%$ of patients did not complete their treatment. At the end of treatment, the majority of patients survived (86.4\%).

Conclusions: Germ cell tumor has various clinical characteristics. Understanding these characteristics will enable clinicians to make a proper diagnosis and provide immediate management that will lead to a better prognosis.

Keywords: Alpha-fetoprotein, teratoma, yolk sac tumor

\section{Introduction}

Germ cell tumor (GCT) is an abnormal tissue development from primordial germ cell that has various clinical manifestations and histopathology. Normally, this primordial germ cell can arise in the ovarium and testicle, ${ }^{1,2}$ as well as in the extragonadal sites including the mediastinum, intracranial, and sacrococcygeal. Most of the patients have intragonadal GCT. $^{3}$ This tumor has numerous histological subtypes. The clinical manifestations vary with tumor site, histologic subtypes, and stages. The main manifestations of GCT are abdominal pain, abdominal distention, and palpable mass at the site of the tumor. ${ }^{4}$ Other manifestations are weight loss and precocious puberty. ${ }^{1}$

This tumor can be benign or malignant.
Three-percent of malignancy in pediatric aged $0-8$ is occupied by GCT and the incidence increase by $15 \%$ during adolescence. ${ }^{3}$ GCT is more common in girls with an incidence of 5.3 per million in girls and 4.3 per million in boys. ${ }^{5}$ Epidemiological study has shown that Asian countries have the highest incidence of GCT, including Indonesia. ${ }^{6}$ Five-years survival rate of this tumor is $98 \%$ in the earlier stage and $80 \%$ for the malignant tumor. ${ }^{3}$

Currently, the study reporting clinical manifestations of pediatric GCT patients in Indonesia is still limited. This study aimed to gather information about clinical manifestations among pediatric GCT patients in Dr. Hasan Sadikin General Hospital, a top referral hospital in West Java. Furthermore, the outcome of the GCT treatment was explored. It is expected that knowing these approaches will help clinicians to get a proper 
diagnosis, immediate management, and a better prognosis.

\section{Methods}

This research design was a cross-sectional study using secondary data from the hospital information system (SIRS), cancer registry, the in-and outpatient medical records. The data of pediatric patients with germ cell tumor (GCT) was collected in AugustSeptember 2019, including pediatric patients who were hospitalized in Dr. Hasan Sadikin General Hospital from 2015 to 2018. The data collection technique in this study was the total sampling method. International Classification of Disease (ICD) with code 10 was used with the site codes for tumor were ovary (C56), testis (C62.9), mediastinum (C37), retroperitoneum (C48), and intracranial (C49). The exclusion criteria were incomplete medical records in histopathology result and stage, and patients who did not do the biopsy. This study had been approved by the Research Ethics Committee of Universitas Padjajaran, Bandung No. 809/UN6.KEP/EC/2019 and by the Medical Research Ethical Committee of Dr. Hasan Sadikin General Hospital, Bandung No.LB.02.01/X.2.2.1/12579/2019.
Variables in this study were patient identities (age of diagnosis and gender), nutritional status, clinical manifestations (at the first visit), pathologic features (site, staging, and histopathology feature of tumor), hematological profiles (hemoglobin level, hematocrit level, leukocyte count, and thrombocyte count), tumor marker such as alpha-fetoprotein (AFP), lactic acid dehydrogenase (LDH) and beta-human chorionic gonadotropin ( $\beta$-hCG), methods of treatment, completeness of treatment and outcome at the end of treatment. To determine the hematological profiles and tumor marker level, the normal values were used, based on gender and age of patients. The stage of GCT was based on the Children's Oncology Group (COG). ${ }^{7}$ Cancer chemotherapy protocol was used to determine the completion of the treatment.

The data were described and presented in the form and table or chart using Microsoft $₫$ Excel 2016 and IBM ${ }^{\circledR}$ SPSS ${ }^{\circledR}$ version 20 .

\section{Results}

There were 206 data fulfilled the ICD codes 10 from the in- and outpatient medical records, however, 24 data were missing

Table 1 Profile and Clinical Manifestation of Pediatric Patients with Germ Cell Tumor in Dr. Hasan Sadikin General Hospital 2015-2018

\begin{tabular}{lcc}
\hline \multicolumn{1}{c}{ Characteristic } & $\mathrm{n}$ & $\mathbf{\%}$ \\
\hline Gender & 10 & \\
Boys & 34 & 22.7 \\
Girl & & 77.3 \\
Age Categories & 15 & \\
$\leq 5$ years & 8 & 34.1 \\
$>5-10$ years & 9 & 18.2 \\
10-15 years & 12 & 20.5 \\
$>15-18$ years & & 27.3 \\
Clinical Manifestation & 43 & \\
Abdominal mass & 15 & 97.7 \\
Abdominal pain & 7 & 34.1 \\
Weight loss & 7 & 15.9 \\
Pale & 6 & 15.9 \\
Abdominal tightening & 5 & 13.6 \\
Intermittent fever & 4 & 11.4 \\
Menstrual disorder & 3 & 9.1 \\
Precocious puberty & 3 & 6.8 \\
Vaginal discharge & 2 & 6.8 \\
Vaginal bleeding & 2 & 4.5 \\
Bronchospasm & & 4.5 \\
\hline
\end{tabular}


Table 2 Nutritional Status and Tumor Features of Pediatric Patients with Germ Cell Tumor in Dr. Hasan Sadikin General Hospital 2015-2018

\begin{tabular}{|c|c|c|c|c|c|c|c|}
\hline \multirow{2}{*}{ Characteristic } & \multicolumn{2}{|c|}{ Gender } & \multicolumn{4}{|c|}{ Age (years) } & \multirow{2}{*}{ n(\%) } \\
\hline & Boy & Girl & $\leq 5$ & $>5-10$ & $>10-15$ & $>15-18$ & \\
\hline \multicolumn{8}{|l|}{ Nutritional Status } \\
\hline Severe malnutrition & 0 & 32 & 5 & 7 & 9 & 11 & $32(72.7)$ \\
\hline Moderate malnutrition & 10 & 0 & 9 & 0 & 0 & 1 & $10(22.7)$ \\
\hline Normal & 0 & 1 & 0 & 1 & 0 & 0 & $1(2.3)$ \\
\hline Overweight & 0 & 1 & 1 & 0 & 0 & 0 & $1(2.3)$ \\
\hline \multicolumn{8}{|l|}{ Tumor Location } \\
\hline Ovarium & 0 & 32 & 5 & 7 & 9 & 11 & $32(72.7)$ \\
\hline Testis & 10 & 0 & 9 & 0 & 0 & 1 & $10(22.7)$ \\
\hline Abdomen & 0 & 1 & 0 & 1 & 0 & 0 & $1(2.3)$ \\
\hline Vagina & 0 & 1 & 1 & 0 & 0 & 0 & $1(2.3)$ \\
\hline \multicolumn{8}{|l|}{ Histopathology } \\
\hline Seminoma & 1 & 0 & 0 & 0 & 0 & 1 & $1(2.3)$ \\
\hline Dysgerminoma & 0 & 11 & 0 & 4 & 5 & 2 & $11(25)$ \\
\hline Germinoma & 0 & 0 & 0 & 0 & 0 & 0 & $0(0)$ \\
\hline Mature teratoma & 0 & 10 & 3 & 3 & 0 & 4 & $10(22.7)$ \\
\hline Immature teratoma & 0 & 2 & 0 & 0 & 1 & 1 & $2(4.5)$ \\
\hline Yolk sac tumor & 9 & 6 & 11 & 0 & 1 & 3 & $15(34.1)$ \\
\hline Choriocarcinoma & 0 & 0 & 0 & 0 & 0 & 0 & $0(0)$ \\
\hline Embryonal carcinoma & 0 & 1 & 1 & 0 & 0 & 0 & $1(2.3)$ \\
\hline Mixed GCT & 0 & 4 & 0 & 1 & 2 & 1 & $4(9.1)$ \\
\hline \multicolumn{8}{|l|}{ Stage } \\
\hline Benign & 0 & 9 & 2 & 2 & 0 & 5 & $9(20.5)$ \\
\hline I & 2 & 12 & 5 & 3 & 2 & 4 & $14(31.8)$ \\
\hline II & 2 & 2 & 2 & 0 & 2 & 0 & $4(9.1)$ \\
\hline III & 5 & 9 & 5 & 3 & 3 & 3 & $14(31.8)$ \\
\hline IV & 1 & 2 & 1 & 0 & 2 & 0 & $3(6.8)$ \\
\hline
\end{tabular}

and 123 data were not GCT cases such as fibroma, cystadenoma mucinosum, and rhabdomyosarcoma. Of the 59 GCT data, only 44 data fulfilled the inclusion criteria, of which 15 data had incomplete histopathology data or staging.

The study showed that the incidence of pediatric GCT was mostly aged2 years old $(13.6 \%)$ and aged 17 years old (11.4\%). The first peak was observed during the first 2 years of life both in girls and boys. The second peak was observed at the age of 15-17 years both in girls and boys. The lowest incidence was found at the age of 3 and 10 years old. Most of GCT patients were females (77.3\%). Among the patient under 5 years old, GCT was more common in boys than girls ( $\mathrm{B}: \mathrm{G}=2: 3$ ). In the older patient, GCT was more common in girls than boys ( $\mathrm{B}: \mathrm{G}=1: 28)$. Overall, GCT was more common in girls than in boys $(B: G=1: 3.4)$.

Majority of patients presented with a combination of signs and symptoms. Almost all of the patients had abdominal mass $(97.7 \%)$, then followed by abdominal pain (34.1\%), and weight loss as well as pale (both 15.9\%). Other symptoms included abdominal tightening, intermittent fever, menstrual disorder, precocious puberty, vaginal discharge, and vaginal bleeding were shown in Table 1.

More than half of GCT patients had normal nutritional status $(59.1 \%)$. Severe malnutrition was found in $11.4 \%$, mostly aged below 10 years old, whereas the moderate malnutrition patients were aged between 1518 years old as shown in Table 2. Overall, GCT was predominantly occurred intragonadal (95.5\%), with the location of the GCT tumor varied with gender as boys had testicular GCT and girls had ovarium GCT (94.1\%), followed by abdominal GCT and vaginal GCT. The testicular GCT was most frequent in the age group below 5 years, whereas ovarian tumors 
Table 3 Treatments of Pediatric Patients with Germ Cell Tumor in Dr. Hasan Sadikin General Hospital 2015-2018

\begin{tabular}{|c|c|c|c|c|c|c|c|}
\hline \multirow{2}{*}{ Treatment } & \multicolumn{2}{|c|}{ Gender } & \multicolumn{4}{|c|}{ Age (years) } & \multirow{2}{*}{ n(\%) } \\
\hline & Boy & Girl & $\leq 5$ & $>5-10$ & $>10-15$ & $>15-18$ & \\
\hline \multicolumn{8}{|l|}{ Benign } \\
\hline Surgery & 0 & 6 & 1 & 0 & 0 & 5 & $6(75)$ \\
\hline Chemotherapy & 0 & 1 & 1 & 0 & 0 & 0 & $1(12.5)$ \\
\hline Surgery+Chemotherapy & 0 & 1 & 0 & 1 & 0 & 0 & $1(12.5)$ \\
\hline \multicolumn{8}{|l|}{ Malignant } \\
\hline Surgery & 1 & 8 & 1 & 3 & 3 & 2 & $9(25)$ \\
\hline Chemotherapy & 0 & 0 & 0 & 0 & 0 & 0 & $0(0)$ \\
\hline Surgery+Chemotherapy & 9 & 18 & 12 & 4 & 6 & 5 & $27(75)$ \\
\hline \multicolumn{8}{|l|}{ Completeness of treatment } \\
\hline Completed Treatment & 3 & 20 & 8 & 6 & 3 & 6 & $23(52.3)$ \\
\hline Dead During Treatment & 2 & 4 & 3 & 0 & 3 & 0 & $6(13.6)$ \\
\hline Interrupted Treatment & 5 & 10 & 4 & 2 & 3 & 6 & $15(34.1)$ \\
\hline \multicolumn{8}{|c|}{ Outcome at the End of Treatment } \\
\hline \multicolumn{8}{|l|}{ Benign } \\
\hline Alive & 0 & 7 & 1 & 1 & 0 & 5 & $7(87.5)$ \\
\hline Dead & 0 & 1 & 1 & 0 & 0 & 0 & $1(12.5)$ \\
\hline \multicolumn{8}{|l|}{ Malignant } \\
\hline Alive & 8 & 23 & 11 & 7 & 6 & 7 & $31(86.1)$ \\
\hline Dead & 2 & 3 & 2 & 0 & 3 & 0 & $5(13.9)$ \\
\hline
\end{tabular}

most frequent in the age group 15 to 18 years.

Histologically, the most frequent GCT were yolk sac tumor (34.1\%), followed by dysgerminoma $(25 \%)$, mature teratoma $(22.7 \%)$, mixed germ cell tumor $(9.1 \%)$, immature teratoma (4.5\%), and seminoma $(2.3 \%)$ as well as embryonal carcinoma $(2.3 \%)$. Germinoma and choriocarcinoma were not found in this study. In boys, yolk sac tumor was predominant, with an age group below 5 years old in most of the cases. In girls, dysgerminoma was predominant with the majority was in the age group between 10 to 15 years old. Only $20.9 \%$ ( 9 of 44 ) patients had benign GCT. The stage of the GCT in this study had stage I (31.8\%), stage II $(9.1 \%)$, stage III $(31.8 \%)$, and stage IV (6.8\%) as depicted in Table 2.

Almost all patients (97.7\%) underwent surgery, either surgery only or combined with chemotherapy, based on the stage and type of histopathology. The majority of benign GCT received only surgery (75\%), while the majority of malignant GCT underwent both surgery and chemotherapy (75\%). The chemotherapy given was the combination of bleomycin, cisplatin, and etoposide, known as the BEP regiment.
Only about half of patients completed their treatment $(52.3 \%)$. There were many factors that patients did not complete their treatment, including died during treatment because of the progressivity of the tumor. The other reasons for incompletion of treatment are a side effect of chemotherapy, sepsis, and loss to followup. However, 1 patient (5\%) had died after completing the last chemotherapy cycle due to his worsening condition. Benign GCT had a better outcome than malignant GCT. Benign GCT at the age group 15-18 years old had a better outcome, whereas in malignant GCT the age group below 5 years old had a better outcome (Table 3).

Anemia was occurred in $79.5 \%$ (35 out of 44), which was common in malignancy. Furthermore, $68.2 \%$ had a low hematocrit level. More than half of the patients had normal leukocytes (61.4\%). No patient had low thrombocytes, most of them (56.8\%) had normal thrombocytes and interestingly, $43.2 \%$ had high thrombocytes.

Tumor markers such as alpha-fetoprotein (AFP), lactic acid dehydrogenase (LDH), and beta-human chorionic gonadotropin ( $\beta$-hCG) were detected in most cases. Overall, the AFP level elevated in most patient of which $6.8 \%$ 
Table 4 Hematological Profiles and Tumor Marker of Pediatric Patients with Germ Cell Tumor in Dr. Hasan Sadikin General Hospital 2015-2018

\begin{tabular}{lcccccc}
\hline \multirow{2}{*}{ Characteristic } & \multicolumn{2}{c}{ Low } & \multicolumn{2}{c}{ Normal } & \multicolumn{2}{c}{ High } \\
\cline { 2 - 7 } & $\mathbf{n}$ & $\mathbf{\%}$ & $\mathbf{n}$ & $\mathbf{\%}$ & $\mathbf{n}$ & $\mathbf{\%}$ \\
\hline Hematological Profiles & & & & & & \\
$\quad$ Hemoglobin & 35 & 79.5 & 9 & 20.5 & 0 & 0 \\
Hematocrit & 30 & 68.2 & 14 & 31.8 & 0 & 0 \\
Leukocyte & 6 & 13.6 & 27 & 61.4 & 11 & 25 \\
$\quad$ Thrombocyte & 0 & 0 & 25 & 56.8 & 19 & 43.2 \\
Tumor Marker & & & & & & \\
AFP & - & - & 10 & 34.5 & 19 & 65.5 \\
LDH & - & - & 15 & 57.7 & 11 & 42.3 \\
$\quad$ B-hCG & - & - & 17 & 73.9 & 6 & 26.1 \\
\hline
\end{tabular}

of patients had AFP level up to $>100.000$. LDH was elevated in 11 patients including patients with yolk sac tumor, dysgerminoma, mature teratoma, and seminoma. $\beta$-hCG was elevated in patients with dysgerminoma, yolk sac tumor and mature teratoma, as shown in Table 4.

At the end of treatment, the majority of GCT patients were alive (86.4\%). Patients with stage I GCT had a better outcome and stage IV GCT had a worse outcomes, of whom (33.3\%) were dead. Seminoma, embryonal carcinoma, and mixed GCT had a better outcome in which all patients were alive. Immature teratoma has the worst outcome in which half of the patients were dead (Table 5).

\section{Discussions}

The study has described the pediatric patients with germ cell tumor (GCT) in Dr. Hasan Sadikin General Hospital 2015-2018 of which girls are predominant (77.3\%). This finding is similar

Table 5 End of Treatment Condition of Pediatric Patients with Germ Cell Tumorin Dr. Hasan Sadikin General Hospital 2015-2018

\begin{tabular}{lcccc}
\hline & \multicolumn{5}{c}{ Condition } \\
\cline { 2 - 5 } Characteristics & \multicolumn{3}{c}{ Alive } & Dead \\
\cline { 2 - 5 } & $\mathbf{n}$ & $\mathbf{0}$ & $\mathbf{n}$ & $\mathbf{\%}$ \\
\hline Stage & 8 & & & \\
Benign & 13 & 88.9 & 1 & 11.1 \\
I & 3 & 86.7 & 1 & 13.3 \\
II & 12 & 75 & 1 & 25 \\
III & 2 & 65.7 & 2 & 14.3 \\
IV & & & 1 & 33.3 \\
Histopathology & 1 & 100 & 0 & \\
Seminoma & 10 & 10 & 1 & 0 \\
Dysgerminoma & 0 & 90.9 & 0 & 10 \\
Germinoma & 9 & 90 & 1 & 9.9 \\
Mature teratoma & 1 & 50 & 1 & 50 \\
Immature teratoma & 12 & 80 & 3 & 20 \\
Yolk sac tumor & 0 & 0 & 0 & 0 \\
Choriocarcinoma & 1 & 100 & 0 & 0 \\
Embryonal carcinoma & 4 & 100 & 0 & 0 \\
Mixed GCT & 38 & 86.4 & 6 & 13.6 \\
Total & & & & \\
\hline
\end{tabular}


to a study in Turkey ${ }^{8}$ that girls are common (61.4\%) among GCT pediatric patients, as well as a study in Pakistan ${ }^{9}(52.7 \%)$. The incidence of pediatric GCT is biphasic; the first peak incidence is observed during the first 2 years of life and the second peak incidence is observed at the age of 15-17 years. Our study has reported a similar peak mostly which is patients aged 2 years old (13.6\%) and aged 17 years old $(11.4 \%)$ and the previous study in Turkey ${ }^{8}$ shows a similar results, as well as another study in the US. ${ }^{10}$ Interestingly, a study in the US has shown the first peak before 1 year old. The older the age, the incidence of ovarian GCT is increased while the testicular GCT is decreased. The striking female predominance relates to the high prevalence of ovarian tumors in adolescent patients. The majority of patients present with a combination of signs and symptoms. Almost all patients have abdominal mass (97.7\%), abdominal pain (34.1\%), and weight loss as well as paleness. The same percentage has been found between abdominal pain and abdominal mass, which are the primary sign and symptoms in children in Turkey $(43.6 \%){ }^{8}$

Interestingly, only one-third of patients have malnutrition which is moderate malnutrition $(27.3 \%)$ and severe malnutrition $(11.4 \%)$, similar to a study in India. ${ }^{11}$ Furthermore, intragonadal GCT have predominantly occurred as also shown in a study from Turkey, ${ }^{8}$ Pakistan, ${ }^{9}$ and Finland. ${ }^{12}$ Mature teratoma is the most common GCT.4,8,12 For example, yolk sac tumors are common (34.1\%), followed by dysgerminoma (25\%), mature teratoma $(22.7 \%)$. In opposite, mature teratoma study is more predominant in the US (74.8\%). ${ }^{4}$ Moreover, GCT is mostly malignant, with various stages, however, many GCT patients have been diagnosed at an early stage of the disease. Depends on the stages and type of histopathology result, most of the patients $(97.7 \%)$ would undergo surgery, or in combination with chemotherapy.

Tumor markers are important in the diagnosis and follow-up. High AFP, LDH, and $\beta$-hCG have been detected in $34.5 \%, 57.7 \%$, and $73.9 \%$ of the subject, respectively. Most of the patients had anemia which is common in malignancy. This can be caused by a chronic disease process, or due to iron deficiency. Furthermore, red cell hypoplasia and megaloblastic anemia in malignancies might occur. ${ }^{13}$

Some limitations found in this study are among others the retrospective study design from a single hospital that has failed to demonstrate the correlation between stage and condition at the end of treatment. A longer period and using multi-centered hospital data, the number of respondents can be increased and further explored.

To conclude, germ cell tumor has many clinical characteristics, therefore, is important to diagnose GCT. Knowing the clinical manifestation, histopathology, hematological profiles, and chemical marker will help clinicians to get a proper diagnosis, immediate management, and a better prognosis.

\section{References}

1. Olson TA. Germ cell tumor. In: Lanzkowsky P, Lipton JM, Fish JD, editors. Lanzkowsky's manual of pediatric hematology and oncology. $6^{\text {th }}$ ed. Cambridge, Massachusetts: Academic Press; 2016. p. 555-67.

2. Hall C, Ritz B, Cockburn M, Davidson TB, Heck JE. Risk of malignant childhood germ cell tumors in relation to demographic, gestational, and perinatal characteristics. Cancer Epidemiol. 2017;46:42-9.

3. Pierce JL, Frazier AL, Amatruda JF. Pediatric germ cell tumors: a developmental perspective. Adv Urol. 2018;2018:9059382.

4. Lin $\mathrm{X}, \mathrm{Wu} \mathrm{D}$, Zheng $\mathrm{N}$, Xia $\mathrm{Q}$ Han $\mathrm{Y}$. Gonadal germ cell tumors in children: a restrospective review of a 10-year singlecenter experience. Medicine (Baltimore). 2017;96(26):e7386.

5. Kaatsch P, Häfner C, Calaminus G, Blettner M, Tulla M. Pediatric germ cell tumors from 1987 to 2011: incidence rates, time trends, and survival. Pediatrics. 2015;135(1):e136-43.

6. Poynter JN, Fonstad R, Tolar J, Spector LG, Ross JA. Incidence of intracranial germ cell tumors by race in the United States, 19922010. J Neurooncol. 2014;120(2):381-8.

7. Cecchetto G. Gonadal germ cell tumors in children and adolescents. J Indian Assoc Pediatr Surg. 2014;19(4):189-94.

8. İncesoy-Özdemir S, Ertem U, Sahin G, Bozkurt C, Yüksek N, Ören AC, et al. Clinical and epidemiological characteristics of children with germ cell tumors: a single center experience in a developing country. Turk J Pediatr. 2017;59(4):410-7.

9. Nasir IUI, Ashraf MI, Ahmed N, Shah MF, Pirzada MT, Syed AA et al. Clinical profile, treatment and survival outcomes of peadiatric germ cell tumours: a Pakistani perspective. J Pak Med Assoc. 2016;66(Suppl 3)(10):S119-21. 
10. Poynter JN, Amatruda JF, Ross JA. Trends in incidence and survival of pediatric and adolescent patients with germ cell tumors in the United States , 1975 to 2006. Cancer. 2010;116(20):4882-91.

11. Srivastava R, Pushpam D, Dhawan D, Bakhshi S. Indicators of malnutrition in children with cancer: a study of 690 patients from a tertiary care cancer center. Indian J Cancer. 2015;52(2):199-201.
12. Pauniaho SL, Saonen J, Helminem M, Heikinheimo O, Vettenranta K, Heikinheimo M. Germ cell tumors in children and adolescents in Finland: trends over 1969-2008. Cancer Causes Control. 2014;25(10):1337-41.

13. Gaspar BL, Sharma P, Das R. Anemia in malignancies: pathogenetic and diagnostic considerations. Hematology. 2015;20(1):18-25. 